S3 File. Correlation between prepregnancy and first-trimester body mass index.

Plots and correlations are displayed for the original dataset and each of the imputated datasets.

Original dataset

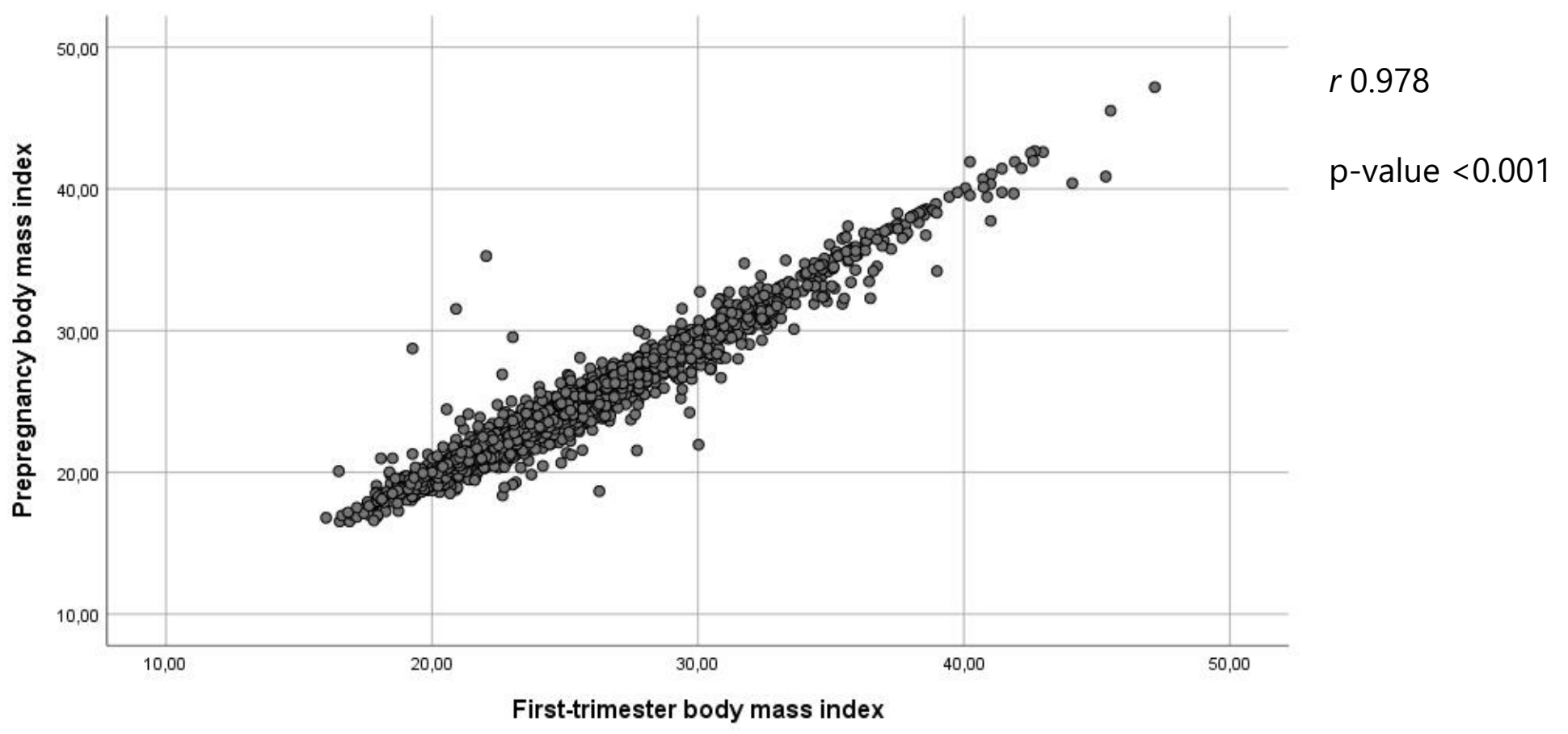


Imputation 1

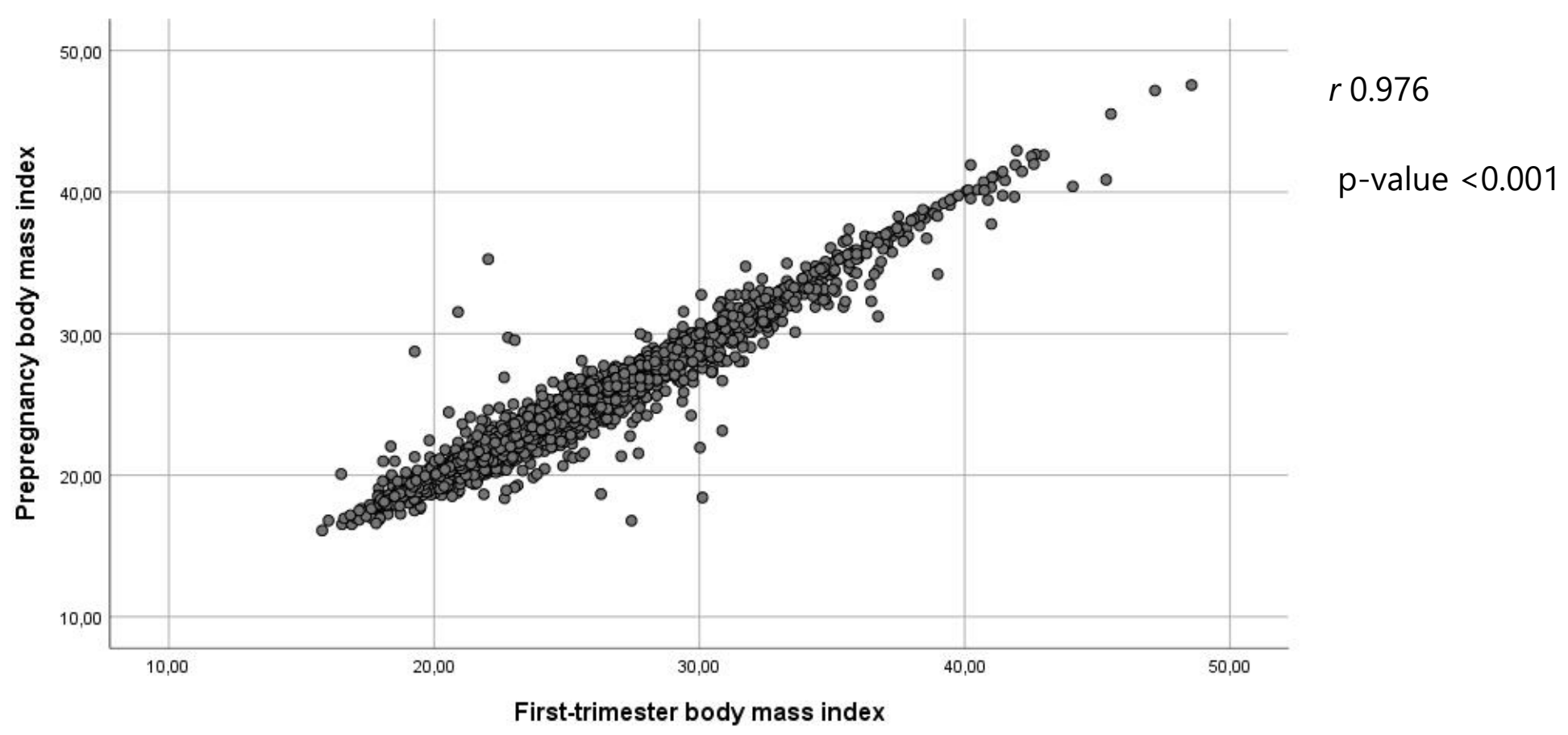

Imputation 2

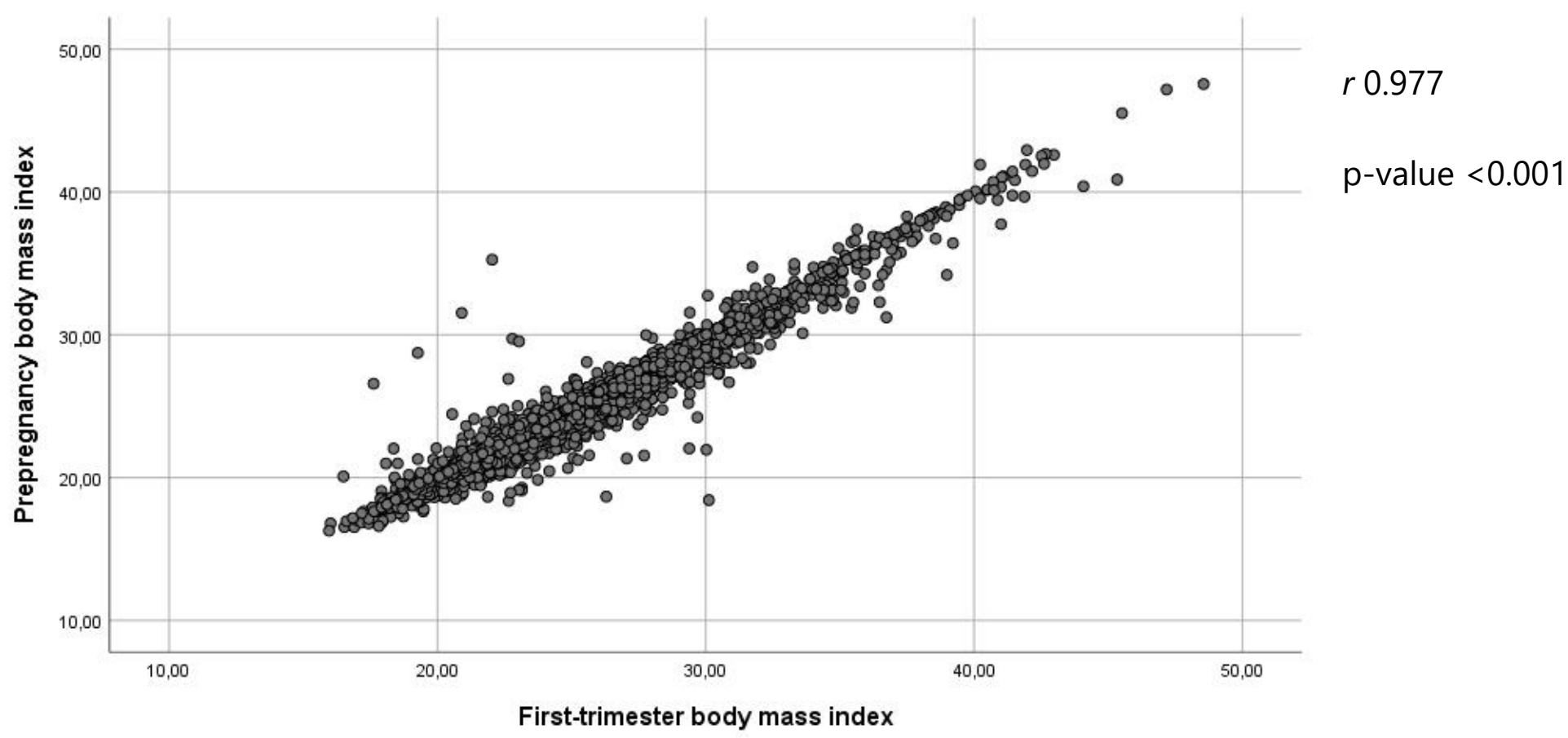


Imputation 3

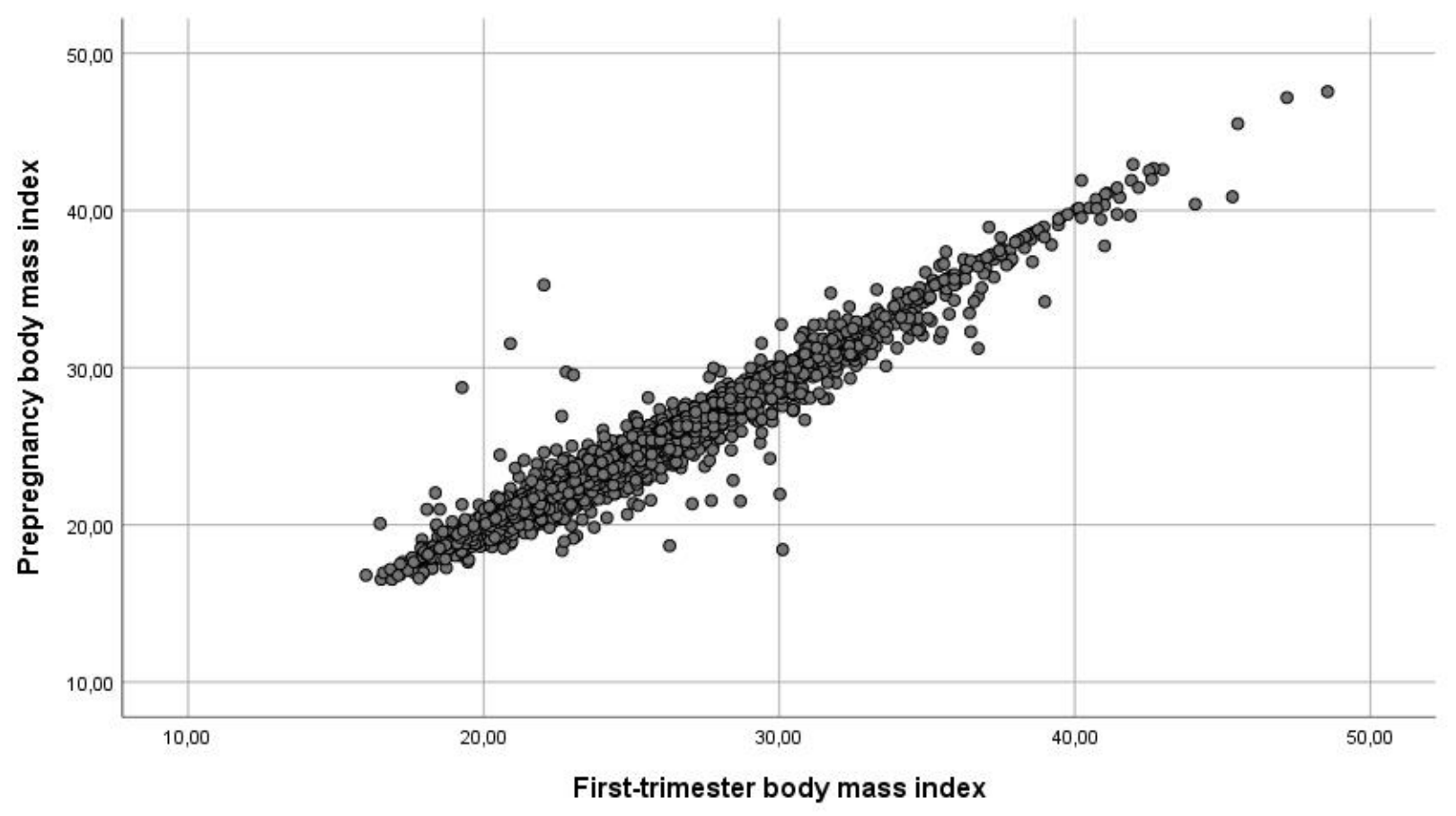

$p$-value $<0.001$

\section{Imputation 4}

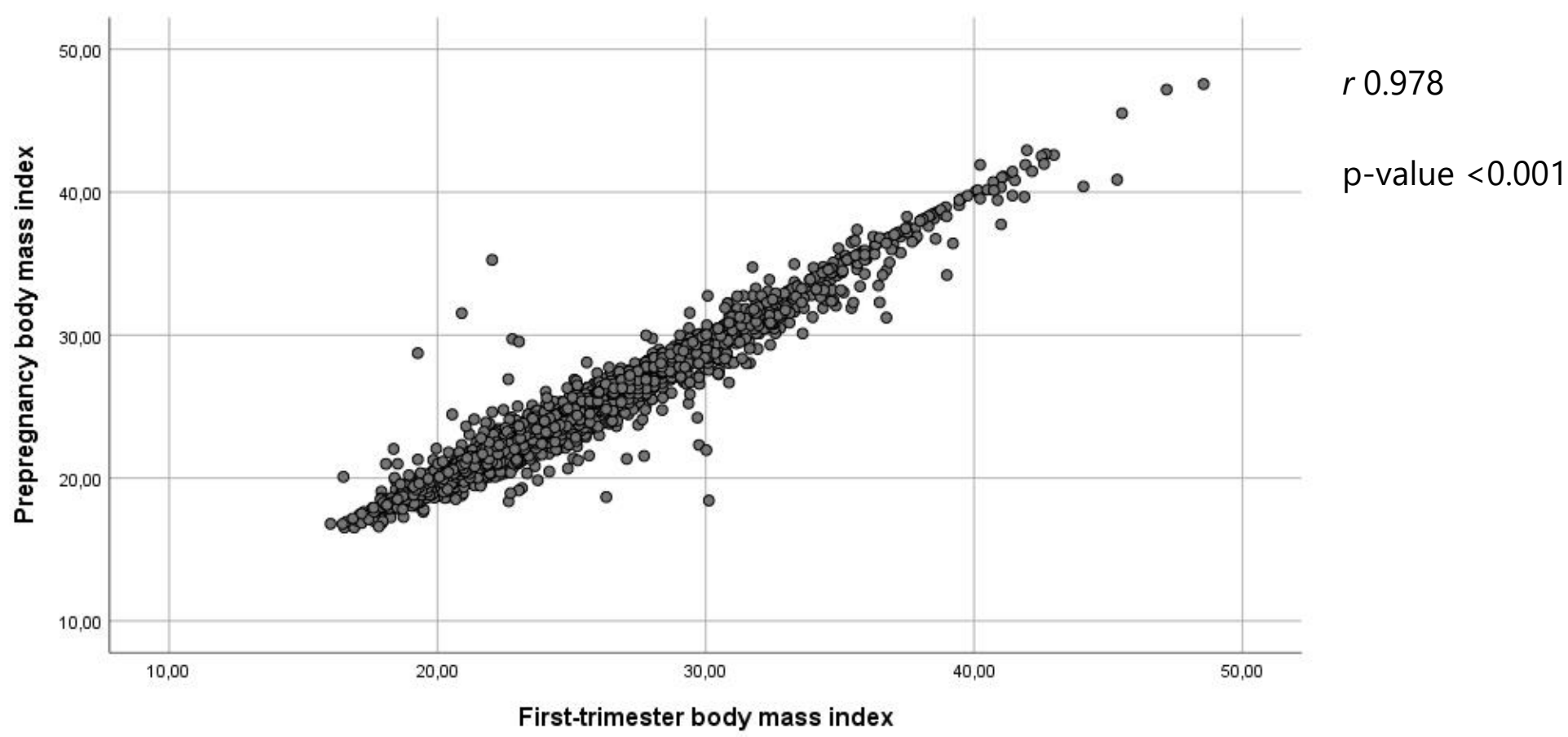




\section{Imputation 5}

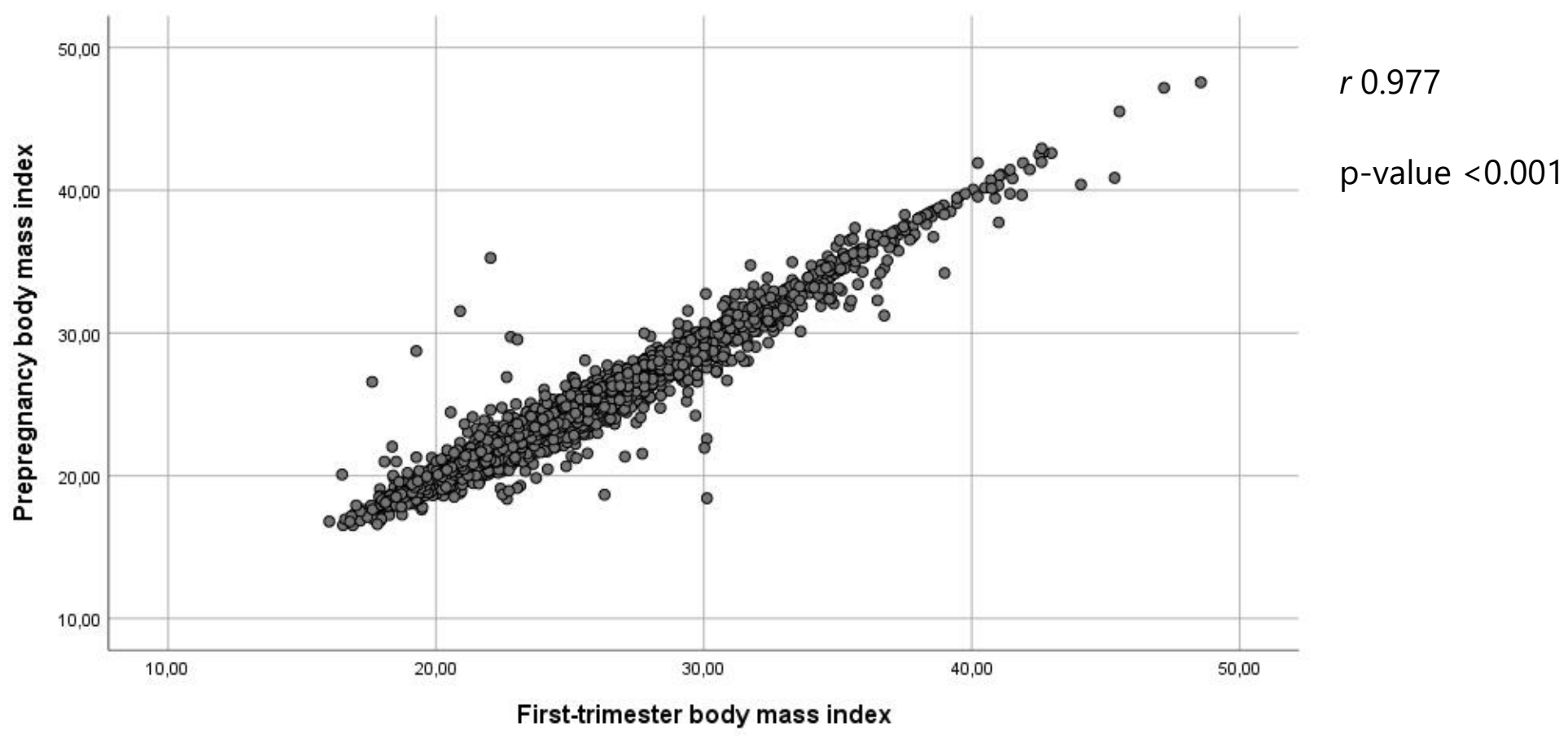

Imputation 6

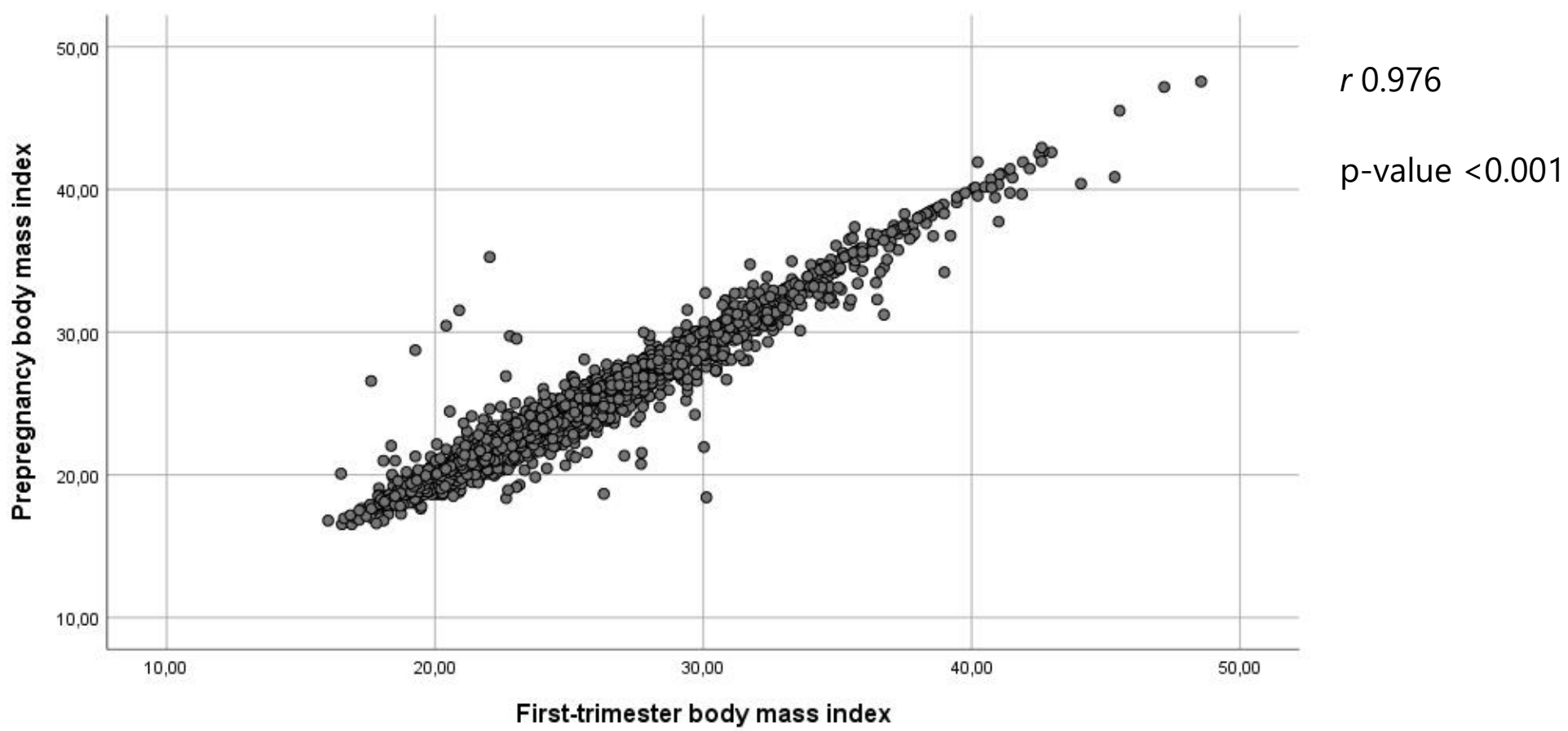




\section{Imputation 7}

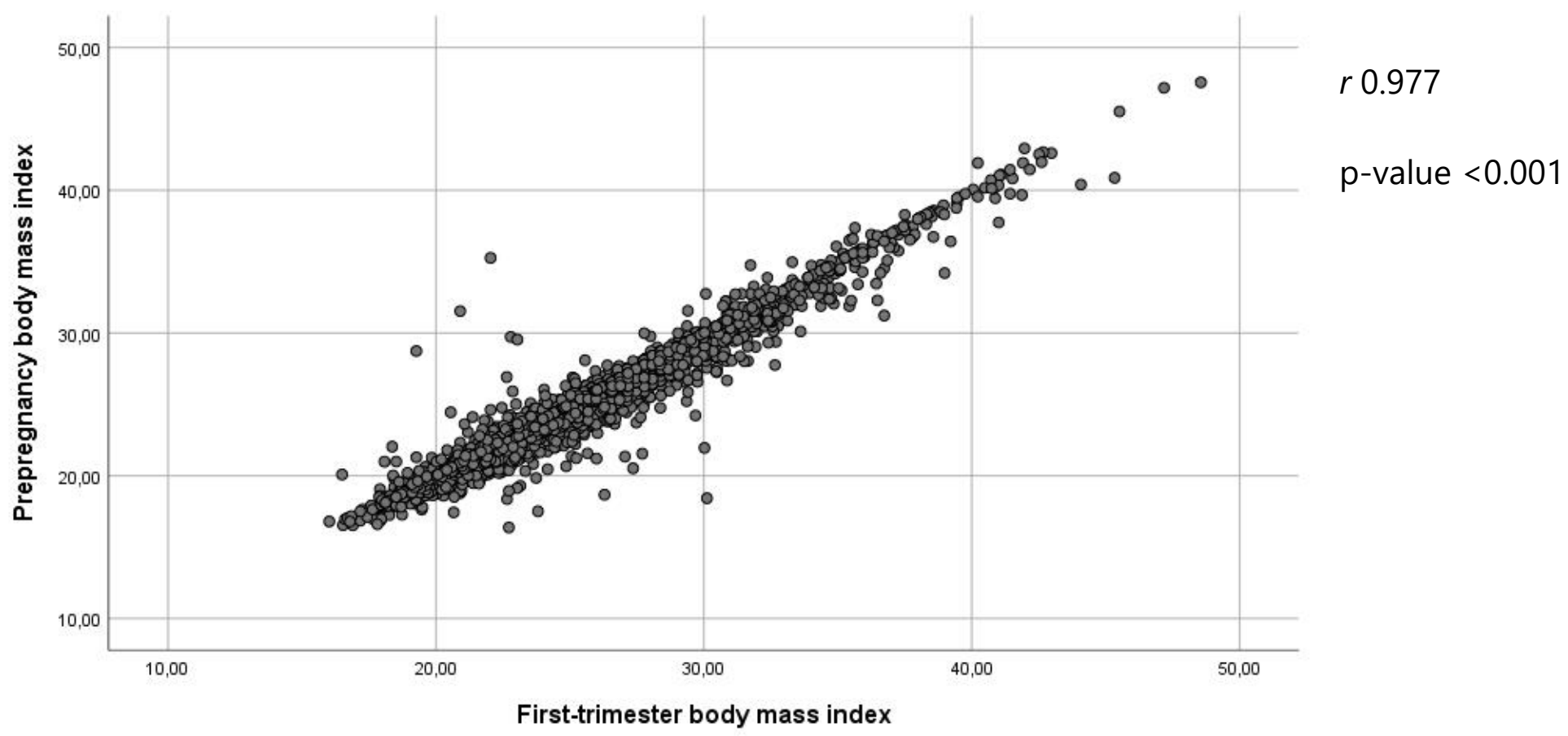

Imputation 8

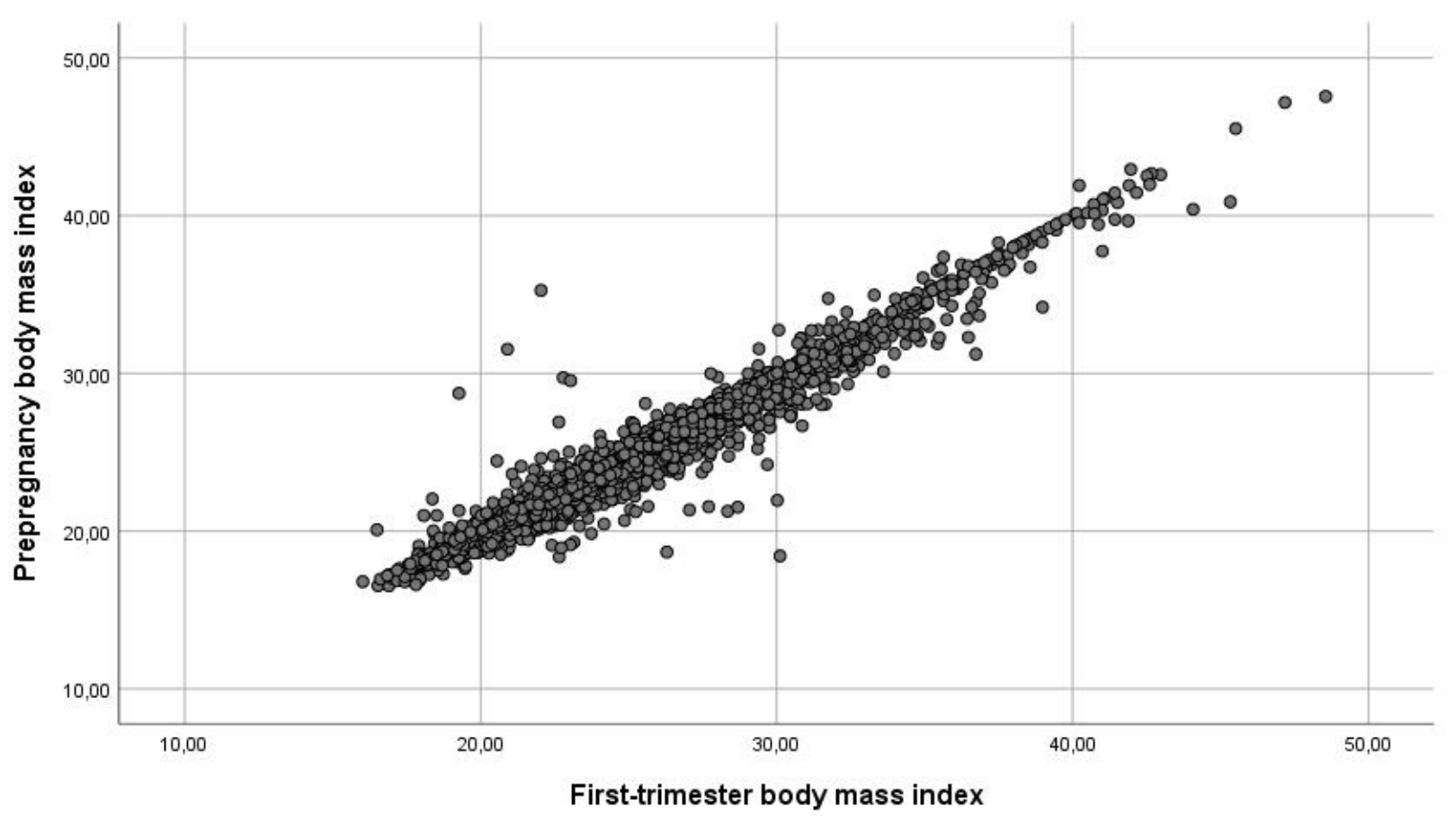

$p$-value $<0.001$ 


\section{Imputation 9}

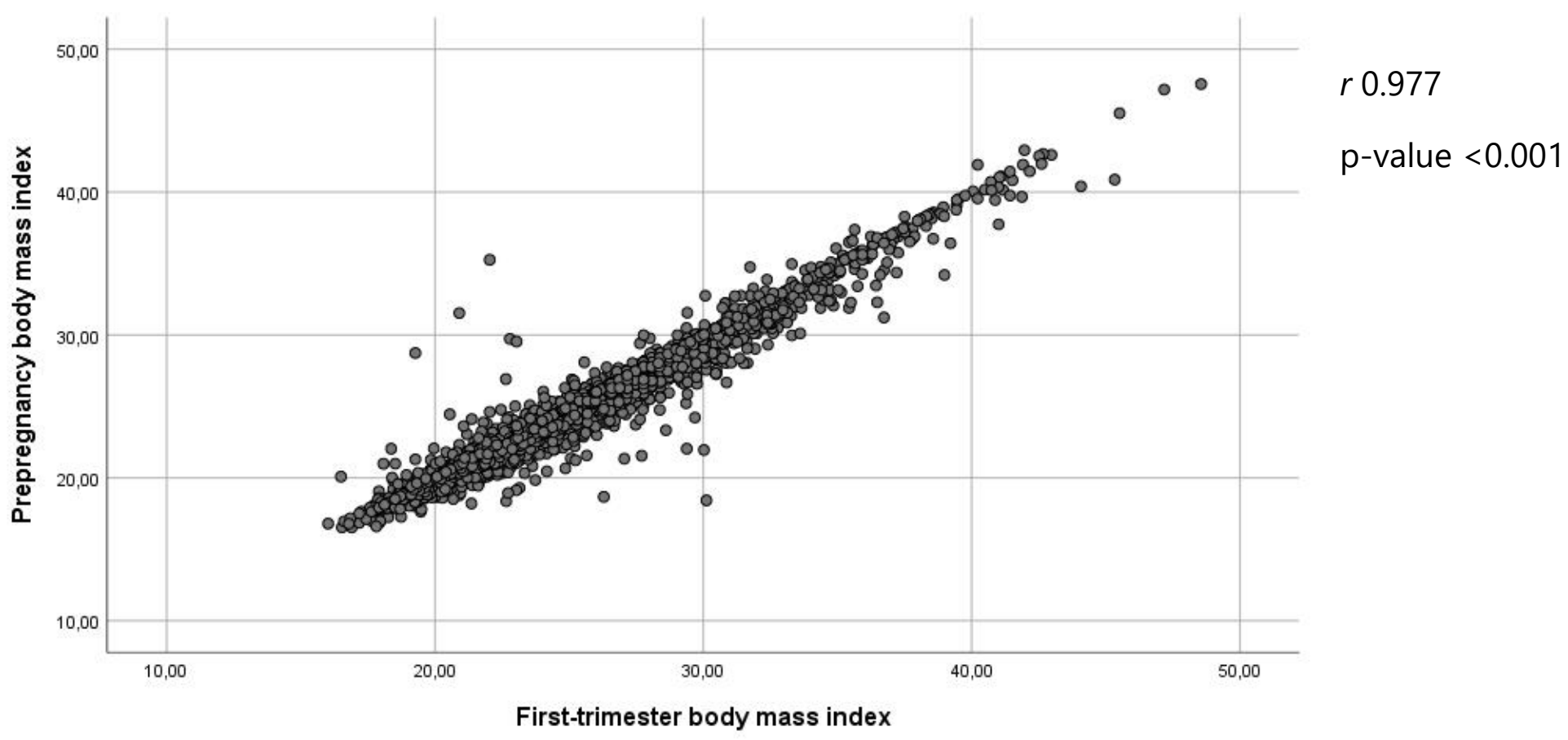

Imputation 10

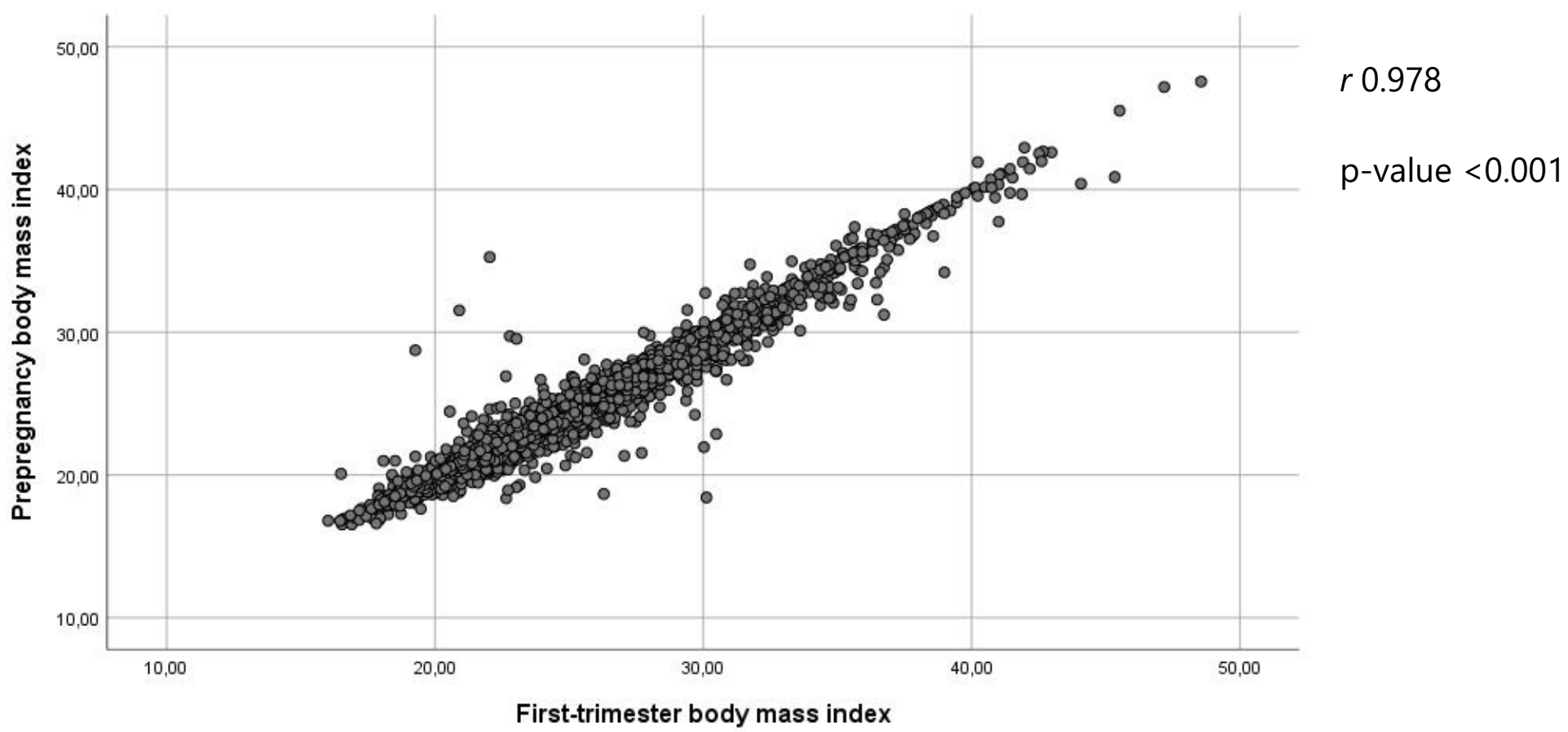

